\title{
Assimilation of altimetric data and mean sea surface height into an eddy-permitting model of the North Atlantic
}

\author{
Peter D. Killworth ${ }^{\mathrm{a}, *}$, C. Dieterich ${ }^{\mathrm{b}}$, C. Le Provost ${ }^{\mathrm{c}}$, A. Oschlies ${ }^{\mathrm{d}}$, \\ J. Willebrand ${ }^{\mathrm{d}}$ \\ a Southampton Oceanography Centre, Empress Dock, Southampton, UK \\ b Alfred-Wegener Institut, Bremerhaven, Germany \\ c LEGOS, Toulouse, France \\ d Institut für Meereskunde, Kiel, Germany
}

\begin{abstract}
This paper shows that the mean flow of an eddy-permitting model can be altered by assimilation of surface height variability, providing that information about the mean sea surface is included, using an adaption of a statistical-dynamical method devised by Oschlies and Willebrand. We show that for a restricted depth range (about $1000 \mathrm{~m}$ ), dynamical knowledge can make up for the null space present in surface data whose temporal extent may be too short to distinguish between vertical modes. The lack of an accurate geoid has meant that most assimilation methods, while representing variability well, have been unable to modify the mean flow to any extent. However, we show that by including several approximate forms for the mean sea surface, the mean interior flow in the upper kilometer can be rapidly adjusted towards reality by the assimilation, with the location of major current systems moved by hundreds of kilometers. (C) 2001 Elsevier Science Ltd. All rights reserved.
\end{abstract}

\section{Contents}

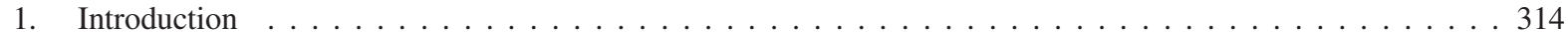

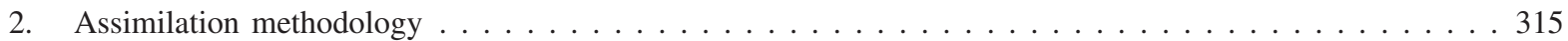

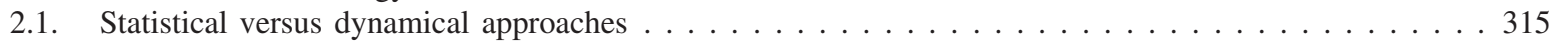

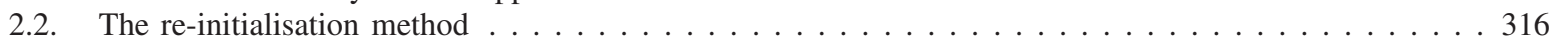

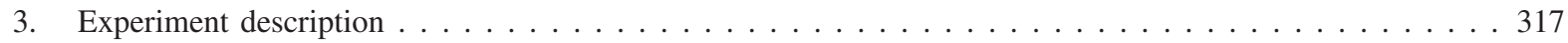

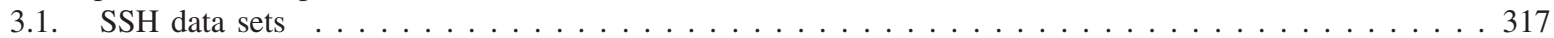

* Corresponding author. Tel.: +44-23-80596202; fax: +44-23-80596204.

E-mail address: peter.d.killworth@soc.soton.sc.uk (P.D. Killworth). 


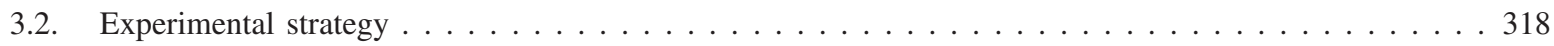

4. Fraternal twin experiment . . . . . . . . . . . . . . . . . . . . . . . . 319

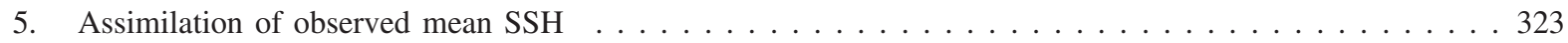

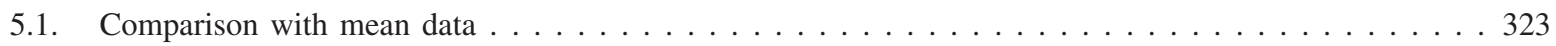

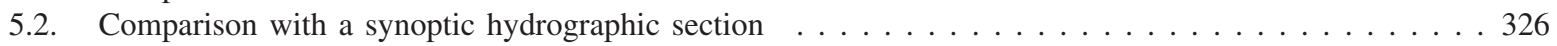

6. Conclusion/discussion . . . . . . . . . . . . . . . . . . . . . . . . . . . . . 329

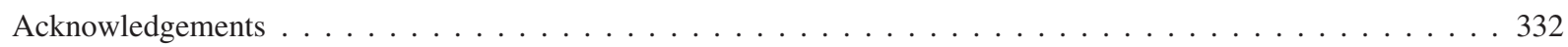

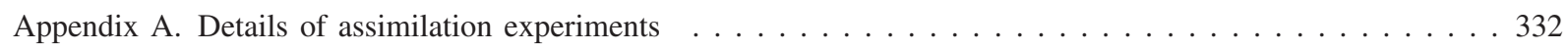

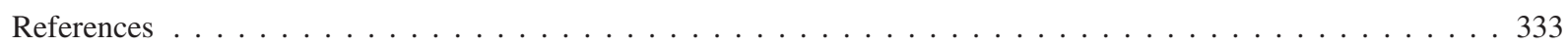

\section{Introduction}

Satellite altimetry has become an important means of observing the ocean, almost globally in space and continuous in time. Much work has been dedicated to the use of altimeter data for analysing the mesoscale variability at the ocean surface (e.g., Le Traon, Rouquet \& Boissier, 1990; Stammer, 1997; Wunsch \& Stammer, 1995). These statistical descriptions are necessarily restricted to the ocean surface. As subsurface in situ observations with a similar coverage than altimetry are generally unavailable, one has to rely on knowledge of ocean dynamics to infer subsurface information from the altimetric data set. The most systematic combination of dynamical information and altimetric observations is obtained by assimilating altimetric data into a numerical ocean model.

A difficulty with any use of altimetric data arises from the sea surface topography consists of an interaction between the geoid and the dynamic topography resulting from ocean currents. Despite improvements in present geoids (Lemoine et al., 1997), these are still not as accurate as direct oceanographic methods to determine the absolute dynamic topography, except at very long wavelengths of some thousand kilometres. Oceanographers interested in mesoscale processes can easily extract the time-varying part of the dynamic topography from the altimeter signal but have to use independent measurements to estimate the time mean. By assimilating only the time-varying part of sea surface height (SSH), we can anticipate that the variability of the flow will be improved, and this has indeed been suggested by Oschlies and Willebrand (1996, hereafter OW) and in many other papers.

However, changes to the mean water mass properties of the model (defined as means over some suitably long time interval) are difficult to achieve if only variability is being assimilated: the changes can occur only indirectly and weakly through action of the nonlinear interaction terms, i.e. divergences of eddy transports. However, apart from regions of rapid advection such as western boundary currents, it is hard to see how substantial changes could occur to the mean flow over large regions, unless the assimilation is carried out over time periods of order of the ocean circulation time scale. 
The experience of OW in using a non-optimal assimilation method confirms this. It is likely that methods, which are statistically optimal, will have similar properties, since systematic model errors with respect to the mean circulation are both large and unknown, as shown by model intercomparisons (Willebrand et al., 2001), and hence error bounds obtained by formal methods will be unreliable. A clear improvement can only be achieved when information on the mean sea surface topography is used somehow.

Here we describe a set of assimilation experiments using an eddy-permitting model of the North Atlantic, simulating the year 1993. These show that the mean characteristics of the model (water mass structure, major current locations, etc.) can be strongly changed when not only sea surface variability, but also a representation of the mean sea surface, is assimilated. Furthermore, when an accurate mean sea surface is used, the accuracy of the mean characteristics of the model is improved. Because of this, we believe our assimilation provides an accurate estimation of the circulation during the period.

Section 2 addresses the methodology used, and Section 3 describes the experiments. Results from a 'fraternal twin' experiment are discussed in Section 4, and changes to the mean flow in Section 5.

\section{Assimilation methodology}

\subsection{Statistical versus dynamical approaches}

A variety of methods, originally developed for meteorology, has been produced to assimilate ocean data into models; (see Ghil \& Malanotte-Rizzoli, 1991, for an extensive review). Oceanographic problems differ from their meteorological counterparts in several respects: poor data coverage; less mature numerical codes; the existence of geometries and boundaries; and, usually, differing requirements.

Of all methods which have been suggested, two stand out as being conceptually the conceptually most straightforward: the adjoint method (Le Dimet \& Talagrand, 1986), and the Kalman filter (e.g., Ghil, Cohn, Tavantzis \& Isaacson, 1981). Both methods are statistically optimal (for a linear model) in the sense that they minimise the covariance of the estimated errors, and both under certain conditions finally yield the same state estimate (Thacker, 1986). However, they both suffer from numerical complexity and high computational cost, requiring either a global minimum to be found in a phase space of enormous size (adjoints) or the time development of an equally enormous covariance matrix of model errors (Kalman filters) unless approximate techniques are used (e.g., Evensen \& Van Leeuwen, 1996). Furthermore, both are based on the idea of minimising the expected error by a maximum likelihood estimate; which may not always be adequate for present ocean models. If the probability distribution of the errors is not Gaussian — which is the case for systematic model errors, for example — the optimised state will in general not be one of maximum likelihood.

A variety of methods which are based on nudging or insertion techniques has been used to combine numerical models and observations (e.g., Holland \& Malanotte-Rizzoli, 1989). Like the Kalman filter, these methods sequentially update successive model forecasts, without being optimal in any sense. The main argument for using nonoptimal methods obviously is a great reduction 
in the computational load. They have, however, been shown to be quite successful in limited applications, e.g. quasi-geostrophic dynamics with low vertical resolution (Hurlburt, Fox \& Metzger, 1990; Capotondi, Holland \& Malanotte-Rizzoli, 1995a,b). With higher vertical resolution, and with more general primitive equation dynamics, we expect a poorer performance from non-optimal schemes.

The fact that the altimeter observes only the ocean surface will, however, cause difficulties with any assimilation method. A single observation of the sea surface topography alone cannot allow a unique determination of the state of the deep ocean. A second measurement taken by the satellite after some time interval restricts the number of possible ocean states consistent with both observations. Fukumori (1995) has suggested that for linear models a sufficiently long time series of surface observations combined with some understanding of ocean dynamics should gradually reveal more and more about the deep ocean.

For a general nonlinear system containing mesoscale eddies, the situation is more complicated. The assimilation times are restricted by the predictability, to a few months at most, i.e. a few circulation times around an eddy. The problem lies in the slow wave speeds of mid- and high latitude baroclinic Rossby waves, which are the predominant mode of ocean adjustment. During the time scale over which the assimilation can be expected to function, the waves do not propagate a sufficient distance to differentiate between vertical wave modes from their surface signatures (indeed, this problem exists even for equatorial wave modes whose speeds are much faster, cf. Weaver \& Anderson, 1997). Thus assimilation of surface properties alone necessarily leads to an underdetermined problem. To deal with this, we must rely either on the knowledge of physics, or on observed (statistical) relationships among variables at different depths, or a combination of both.

An example of a physically-based method has been given by Cooper and Haines (1996). Their method seeks to conserve density and linear potential vorticity in the assimilation step, this is attractive in that it avoids the use of uncertain model statistics. However, their identical twin experiments demonstrate that their method performs poorly in weakly stratified, high latitude regions. An example of a purely statistical method has been given by Ezer and Mellor (1994) who utilise covariances between SSH and interior variables. The method of OW, which is described in the following section, may be viewed as a combination in that it uses both dynamical concepts (geostrophy and conservation of water mass properties) as well as statistical information.

\subsection{The re-initialisation method}

In this section we briefly describe the scheme for assimilating altimeter data developed by OW, and used to carry out our the assimilation. Although it is by no means perfect, it is as successful a method as any of the other existing attempts that have been made to assimilate real altimeter data into a basin-scale or larger eddy-permitting primitive-equation model with realistic geometry (cf. Tokmakian, 1997; Fox \& Haines, 1996). The OW method uses a non-optimal re-initialisation, since the costs of the optimal methods are too high for use in such cases.

The basic concept of all sequential data assimilation methods can be expressed as

$$
\mathbf{x}^{\mathrm{a}}=\mathbf{x}^{\mathrm{f}}+\mathbf{K}\left(\mathbf{y}^{\mathrm{obs}}-\mathbf{H} \mathbf{x}^{\mathrm{f}}\right)
$$

where $\mathbf{x}$ is the state vector of the numerical ocean circulation model, with indices $f$ and a referring 
to forecast and analysis respectively. The operator $\mathbf{K}$, is a projection of the difference between measured variables $\mathbf{y}^{\mathrm{obs}}$ and their model forecast counterpart $\mathbf{y}^{\mathrm{f}} \equiv \mathbf{H} \mathbf{x}^{\mathrm{f}}$ onto the model state space. An assimilation cycle consists of: (a) halting the model integration at each observation time to obtain a model forecast $\mathbf{x}^{\mathrm{f}}$ and associated $\mathbf{y}^{\mathrm{f}}$; (b) computing the correction $\mathbf{K}\left(\mathbf{y}^{\text {obs }}-\mathbf{H} \mathbf{x}^{\mathrm{f}}\right)$ required to adjust the model state to the observations; and (c) restarting the model integration from the updated, or analysed, state $\mathbf{x}^{\mathrm{a}}$.

The method of OW decomposes $\mathbf{K}$ into three distinct operations to be applied successively (details of these are given in their paper and only a summary is given here). A first operator, A, is used to project the observed model-data SSH misfit onto dynamically consistent corrections to the velocity and density fields (i.e., the fields observable by altimetry) of the model forecast. Surface geostrophic misfits, known from the data, are projected downwards over the top $1000 \mathrm{~m}$, using a model-derived correlation function. The use of geostrophy avoids strong excitation of gravity waves. (This choice selects part of the nullspace of the system.) The second operator, $\mathbf{B}$, is a weighting matrix accounting for the relative accuracies of observations and model forecast. Model errors are approximated, as is traditional given our lack of knowledge, by the variance of the model variables without assimilation. Observational errors were taken as the error variance from the objective mapping algorithm. A further aspect of the nullspace must be determined, using operator $\mathbf{C}$, which partitions the weighted density increments computed by $\mathbf{B} \cdot \mathbf{A}$ into increments of temperature and salinity, conserving water mass properties as closely as possible. Eq. (1) may then be rewritten as

$$
\mathbf{x}^{\mathrm{a}}=\mathbf{x}^{\mathrm{f}}+\mathbf{C} \cdot \mathbf{B} \cdot \mathbf{A}\left(\mathbf{y}^{\text {obs }}-\mathbf{H} \mathbf{x}^{\mathrm{f}}\right)
$$

It is not our intent here to discuss the behaviour of this method, or its dynamical effect on the results; the reader is referred to OW (e.g. their Fig. 11), who show and fully discuss the response to a single assimilative step.

We now discuss the changes relevant for the assimilation of a mean surface height field, rather than the temporal residuals used by OW. Given maps of the altimetric SSH residuals, $\delta \eta^{\text {obs }}$, plus a mean SSH field, $\bar{\eta}$, it is straightforward to compute the model-data misfit $\eta^{\text {obs }}-\eta^{\mathrm{f}}$, where $\eta^{\mathrm{obs}}=\delta \eta^{\mathrm{obs}}+\bar{\eta}$ denotes the observed total $\mathrm{SSH}$, and $\eta^{\mathrm{f}}$ is the corresponding model forecast, corresponding to $\mathbf{H} \mathbf{x}^{\mathrm{f}}$ in Eq. (2). OW reduced the difference $\left(\eta^{\text {obs }}-\eta^{\mathrm{f}}\right)$ to $\left(\delta \eta^{\text {obs }}-\delta \eta^{\mathrm{f}}\right)$ by assuming that both modelled and observed SSH were referenced to the same mean surface. Here, we reference the altimetric residuals to a mean SSH, usually the Singh and Kelly (1997) mean (see below), $\bar{\eta}^{\mathrm{SK}}$ and the residuals of the model forecast to the model mean $\mathrm{SSH}, \bar{\eta}^{\mathrm{mod}}$, to obtain

$$
\Delta \eta=\eta^{\mathrm{obs}}-\eta^{\mathrm{f}}=\delta \eta^{\mathrm{obs}}+\bar{\eta}^{\mathrm{sK}}-\delta \eta^{\mathrm{f}}-\bar{\eta}^{\mathrm{mod}}
$$

The misfit $\Delta \eta$ is then put into the algorithm developed by OW.

\section{Experiment description}

\subsection{SSH data sets}

The data from the simultaneous altimetric mission of ERS-1 and TOPEX/POSEIDON (T/P) are used in this study. For T/P, the sea level anomaly can be determined with a precision better 
than $5 \mathrm{~cm} \mathrm{rms}$, because of the outstanding quality of the orbit determination (error about $2 \mathrm{~cm}$ rms; Nouel et al., 1994). For ERS-1, the radar altimeter has about the same accuracy than for $\mathrm{T} / \mathrm{P}$, but the orbit determination is less good $(\approx 15 \mathrm{~cm} \mathrm{rms}$; Massmann, Reigber, Kning, Raimondo \& Rajasenan, 1993; Scharroo, Wakker \& Mets, 1993). From October 1992 to December 1993, the two spacecraft were operating simultaneously with suitable orbit characteristics for mesoscale studies (10 days repeat orbit and about $315 \mathrm{~km}$ equator inter-track for T/P; 35 days repeat orbit and about $80 \mathrm{~km}$ equator inter-track for ERS-1), and the high orbit quality of T/P was used to reduce the orbit errors of ERS-1 by minimising the differences at ERS-T/P cross-over points (Le Traon, Gaspar, Bouyssel \& Makhmara, 1995). The resulting high quality combined T/P and ERS-1 data set (sea level anomaly error $\approx 5 \mathrm{~cm} \mathrm{rms}$ ) has been used for all assimilations reported here. We have chosen not to extend the run beyond this point as errors in the SSH data would become larger.

An objective analysis routine, described in $\mathrm{OW}$, was used to interpolate the altimetric data onto the model grid. Five-daily maps of the altimetric signal as well as of the expected error variance were produced for the one-year period October 15, 1992 to October 15, 1993.

No accurate estimate of the mean SSH is available for the entire North Atlantic. In a limited region $\left(77^{\circ} \mathrm{W}-30^{\circ} \mathrm{W}\right.$ and $\left.25^{\circ} \mathrm{N}-55^{\circ} \mathrm{N}\right)$, however, a monthly data set provided by Singh and Kelly (1997), exists, based on a combination of historical hydrographic and satellite measurements, which covers the period of our assimilation experiments. When we have used this data set (which is presumably more accurate than any other estimate based on hydrography alone), no information about either the mean or the anomalous SSH is used outside this region. We also make use of model-derived fields (see below) which are not subject to areal restriction.

\subsection{Experimental strategy}

The DYNAMO intercomparison of three different models (Willebrand et al., 2001, henceforth W01), showed that each of three different models of the North Atlantic had strengths and weaknesses (the latter to be improved by assimilation). The prognostic model used for the assimilation is identical to the MOM-based level model described and analysed in W01. An example of the features which we hoped could be improved by the assimilation is the rather poor reproduction of the surface heat flux in certain regions of this model, as compared with climatological estimates or with the ECMWF fields used for forcing (Fig. 2a). The surface heat flux was given as $Q_{1}+Q_{2}$ ( $T_{\text {observed }}-T_{\text {surface }}$ ), where $Q_{1}$ and $Q_{2}$ are from Barnier, Siefridt and Marchesiello (1995). The saline forcing was a relaxation to monthly values. Between 40 and $50^{\circ} \mathrm{N}$, the model shows excessive heat fluxes, including a substantial heat gain around $40^{\circ} \mathrm{W}$ (cf. Fig. 2b). As discussed in W01, these are caused by the misplacement of the Gulf Stream extension eastwards, in other words by a systematic error in this model.

In a first experiment, we have used the method by $\mathrm{OW}$ to assimilate altimetric sea surface height anomalies only. We thus expect to improve the model's variability but not the systematic errors in the mean characteristics of the model.

A common way to test the performance of an assimilation scheme is to perform identical twin experiments. Unfortunately, such experiments cannot determine whether assimilation of the mean SSH can remove the systematic error above, as all the model realisations possess the same error. However, the existence of the results from different models integrated under nearly identical 
conditions provided us with a unique opportunity to perform what might be called a fraternal twin experiment.

A better siting of the Gulf Stream extension in the isopycnic model enables it to reproduce the heat fluxes somewhat better (cf. Fig. 2c). Whether or not the isopycnic model is closer to the truth than the level model in this region is immaterial; it is, at all events, different and thus provides a different realisation of the mean flow. Differences also exist in terms of the models' mean sea surface height in the vicinity of the Gulf Stream (cf. Fig. 12 of W01). All have a region of strong east-west gradient, but the longitude of this region varies between models. In particular, the level model, as a result of the misplacement of the Gulf Stream extension, has a strong SSH gradient at $30^{\circ} \mathrm{W}$, whereas the isopycnic model has its strong gradient at $42^{\circ} \mathrm{W}$.

Hence we have considered the isopycnal model as a non-identical twin of the level model, and have assimilated the isopycnic model's mean SSH into the level model. This should allow us to determine not only how far the mean SSH distribution is changed towards that of its twin, but also to what extent the interior state can be modified towards the corresponding state of the twin model.

Finally, we have performed an assimilation with what might be considered a more realistic mean SSH field, i.e. the data set provided by Singh and Kelly (1997) described above.

Our experiments, then, comprise:

1. a 'control' experiment, a prognostic integration with 1993 surface forcing data, using no assimilation;

2. a 'standard assimilation', in which an SSH is assimilated that consists of the altimetric sea surface height anomalies to which the five-year mean SSH from the control run were added;

3. an 'isopycnic assimilation', using the mean SSH from a 5-year prognostic simulation with the DYNAMO isopycnic model;

4. a 'mean SSH assimilation', using the mean SSH from Singh and Kelly (1997). The assimilation has, however, been restricted to the area $77^{\circ} \mathrm{W}-30^{\circ} \mathrm{W}$ and $25^{\circ} \mathrm{N}-55^{\circ} \mathrm{N}$.

Further details of the experiments are given in the appendix. The following analysis concentrates on mean flow effects to the exclusion of variability, since as with most other assimilation efforts, the sea surface variability, being strongly tied to what is being assimilated, is naturally well reproduced.

\section{Fraternal twin experiment}

Fig. 1 shows the time-mean SSH for the control run, the Singh and Kelly (1997) data, and the mean SSH assimilation. The mean pathway of the NAC according to the Singh and Kelly (1997) analysis is associated with the sharp front at around $42^{\circ} \mathrm{W}$. In the control run the front is weaker, and located at $32^{\circ} \mathrm{W}$. The mean SSH assimilation nearly perfectly matches the location of the main front, though it is somewhat weaker, and thus implies reduced recirculation on the eastern flank.

As the SSH is the variable which is assimilated into the model, it is hardly surprising that the $\mathrm{SSH}$ in the isopycnic assimilation experiment (not shown) very closely resembles the SSH of the isopycnic model. Likewise, for the near-surface currents, which are dynamically coupled to the 
(a)

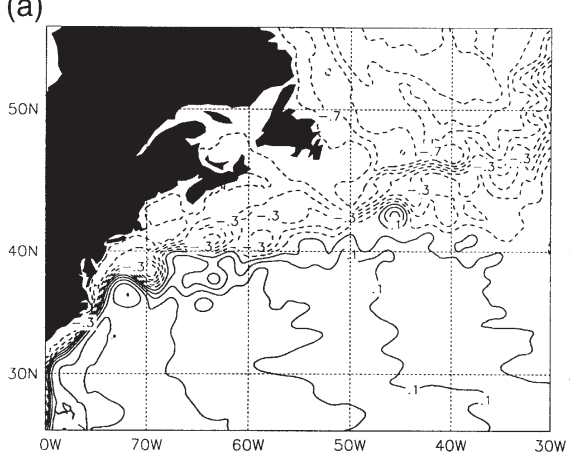

(b)

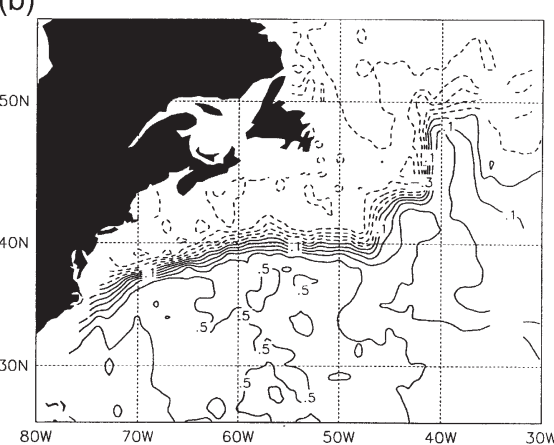

(c)

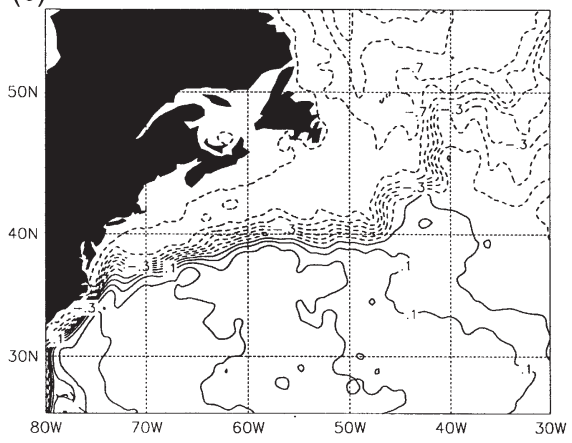

Fig. 1. Mean sea surface height fields (m), ci 0.1 m, dashed lines negative. (a) control run, (b) Singh and Kelly (1997) data, (c) mean SSH assimilation run.

$\mathrm{SSH}$, the assimilation yields almost perfect agreement. It is, however, not obvious to what degree those fields which are less tightly related to SSH resemble the respective fields of the twin experiment. Although the assimilation covered the entire North Atlantic north of $20^{\circ} \mathrm{S}$, we will restrict the following discussion to the western North Atlantic where the discrepancies between control and isopycnic model are largest.

Fig. 2 shows the surface heat fluxes of the different models. As noted above, these are strongly tied to the position of the surface fronts through the relaxation term in the heat flux, and so serve as sensitive indicators of frontal positioning and surface circulation in the models. The pattern of the flux of the isopycnic assimilation experiment (Fig. 2d) is very close to that of its twin (Fig. 2c), and the unrealistic heat uptake east of the Grand Banks in the control run (Fig. 2b) is completely removed. Compared with the twin experiment, the heat loss is slightly weaker over the Gulf Stream, and somewhat stronger over the North Atlantic Current (NAC). Fig. 2e shows a maximum heat loss close to the coast, in qualitative agreement with the ECMWF analysis (Fig. 2a). In general the mean SSH has less extreme heat gains and losses than the other runs, and is thus probably more realistic. However, the region of heat loss is much narrower than in the ECMWF fluxes (Fig. 2a), and has a region of small ocean heat gain towards the centre of the subtropical gyre. Also, the heat gain over the Grand Banks is much more intense than in the atmospheric analysis. The near-surface temperature field (not shown) displays a similar degree of agreement with the twin experiment, confirming that the surface heat budget simulation is 
(a)

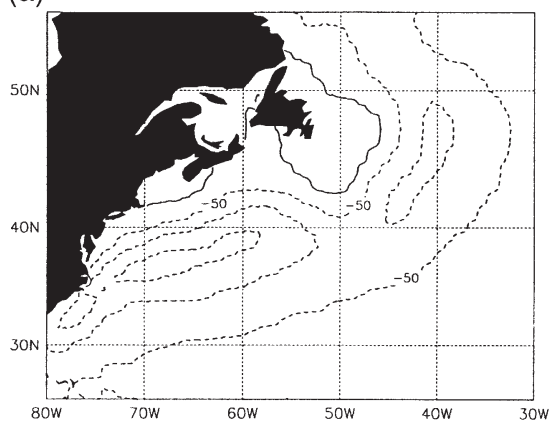

(c)

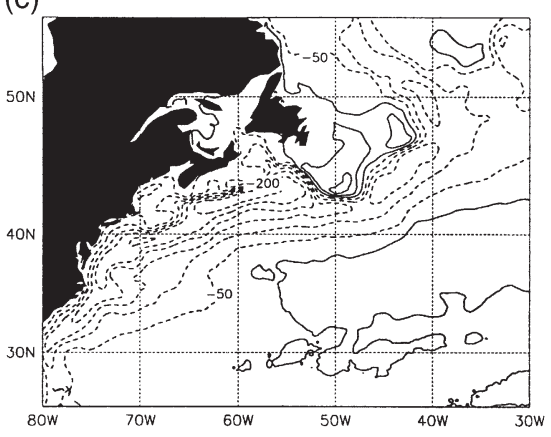

(b)

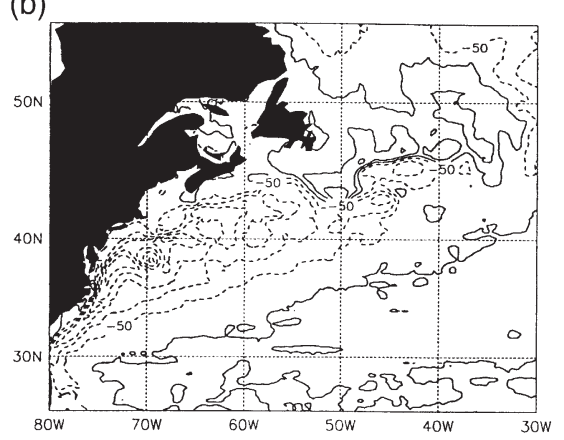

(d)

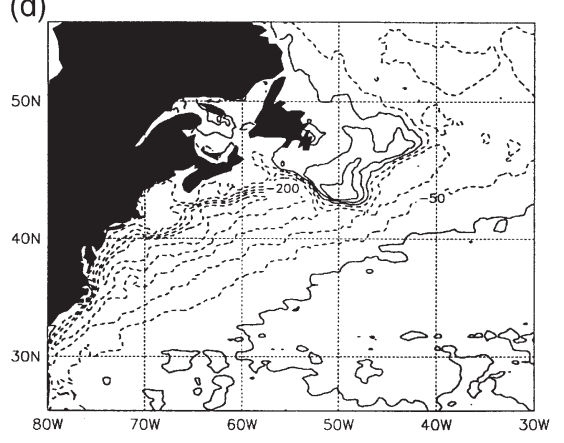

(e)

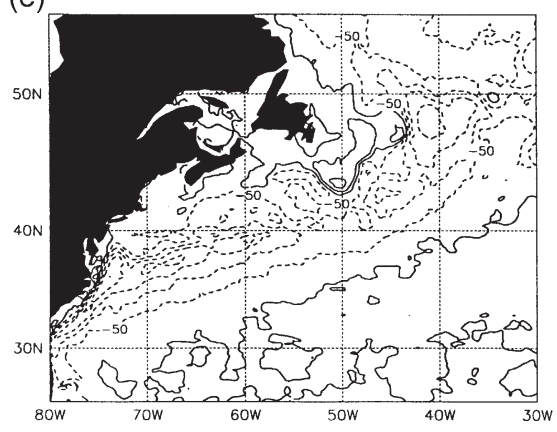

Fig. 2. Annual mean surface heat flux $\left(\mathrm{W} / \mathrm{m}^{2}\right)$, ci $50 \mathrm{~W} / \mathrm{m}^{2}$, dashed lines negative, in the western North Atlantic. (a) ECMWF 1986-1988 climatology, (b) control experiment, (c) isopycnal model, (d) isopycnal twin experiment, (e) mean SSH assimilation experiment.

mostly controlled by near-surface currents. Thus the more realistic heat flux in the mean SSH run reflects the more accurate positioning of the mean current systems.

As seen from Fig. 3, the agreement is not restricted to the near-surface fields. At $48^{\circ} \mathrm{N}$, the temperature section in the control run (Fig. 3b) shows a region of stronger gradients near $30^{\circ} \mathrm{W}$, which extend through the upper kilometer, associated with the unrealistic path of the NAC. In the twin experiment (Fig. 3c), strong gradients in the upper ocean are seen near $42^{\circ} \mathrm{W}$ but not at all near $30^{\circ} \mathrm{W}$. The isopycnic assimilation (Fig. $3 \mathrm{~d}$ ) is in between, and while the front at $42^{\circ} \mathrm{W}$ is not as concentrated as in the twin experiment, the erroneous feature at $30^{\circ} \mathrm{W}$ is largely gone.

The meridional velocity at $48^{\circ} \mathrm{N}$ is shown in Fig. 4. The erroneous northward flow near $30^{\circ} \mathrm{W}$ 
(a)

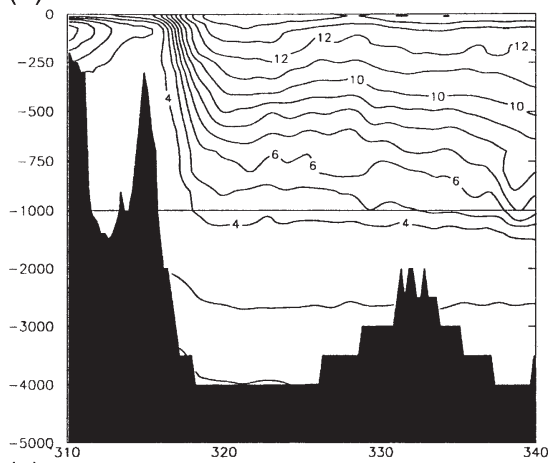

(c)

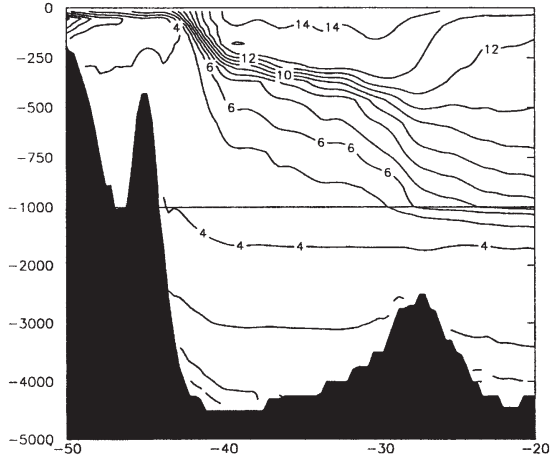

(b)

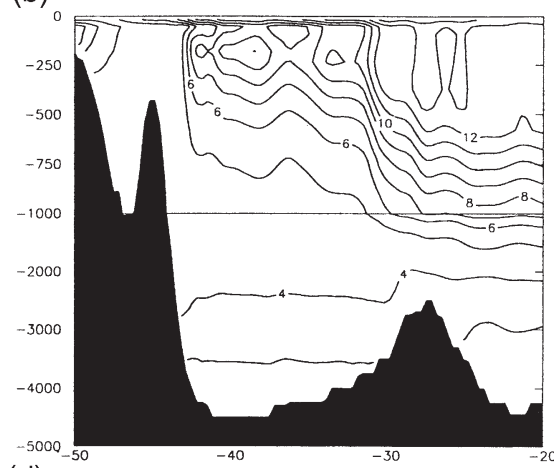

(d)

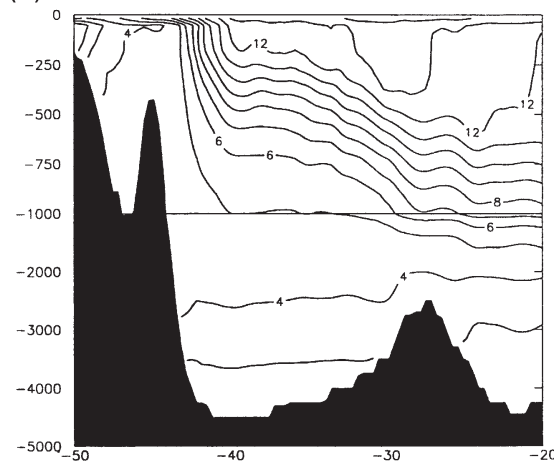

(e)

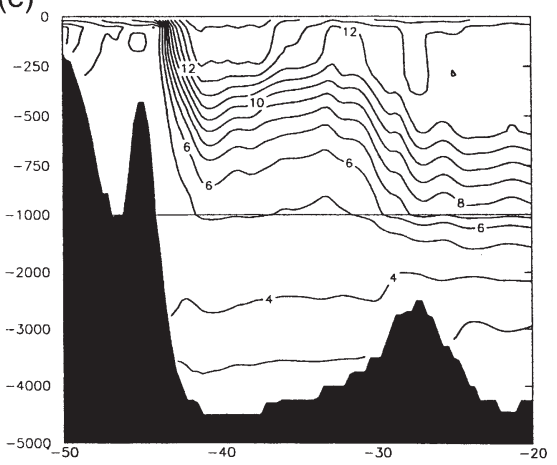

Fig. 3. Section of potential temperature at $48^{\circ} \mathrm{N}$, in ${ }^{\circ} \mathrm{C}$, ci $1{ }^{\circ} \mathrm{C}$; thick line shows $10^{\circ} \mathrm{C}$ contour. (a) From Boyer and Levitus (1997) (b) control experiment, (c) isopycnal model, (d) isopycnal twin experiment, (e) mean SSH assimilation experiment. In (e), assimilation only occurs west of $30^{\circ} \mathrm{W}$.

in the control run (Fig. 4a) extends nearly to $1000 \mathrm{~m}$, with two clearly distinguishable maxima. This flow is not present in the twin experiment (Fig. 4b), and is almost completely removed in the isopycnic assimilation run (Fig. 4c). At the same time, the northward flow at $42^{\circ} \mathrm{N}$ which is rather weak in the control run, now resembles the flow in the twin experiment in the upper kilometer. Below $1000 \mathrm{~m}$, changes of the flow field are small. In particular, the concentrated southward flow around $2000 \mathrm{~m}$ at the western flank of the Mid-Atlantic Ridge which constitutes the main transport of North Atlantic Deep Water has not been removed. 
(a)

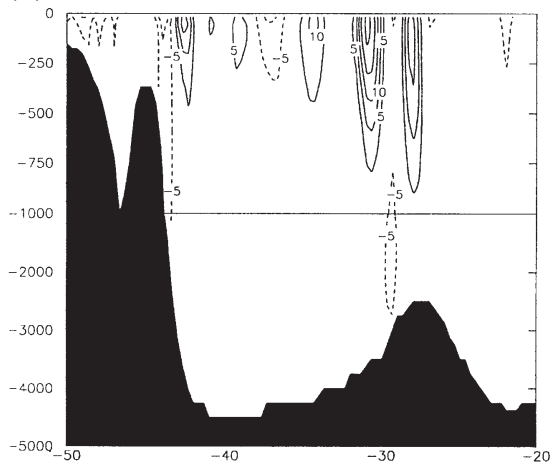

(c)

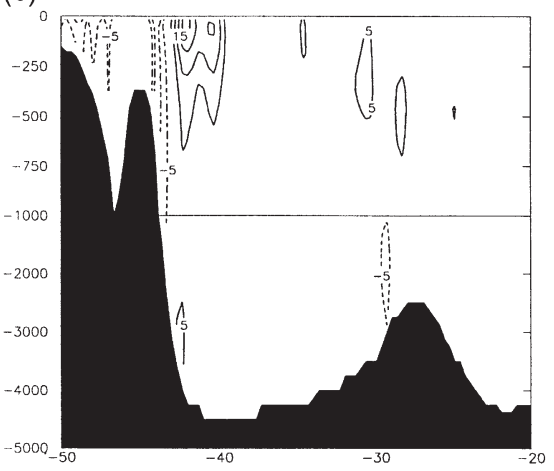

(b)

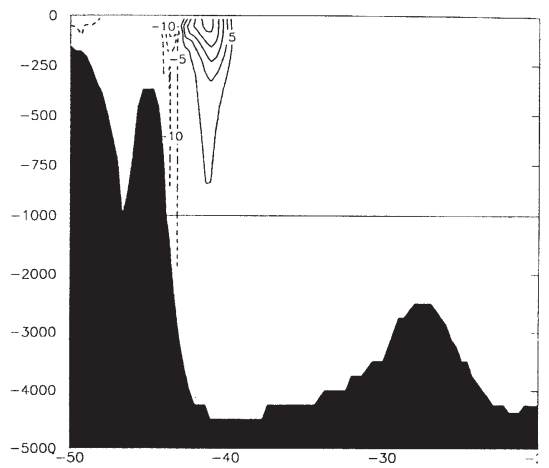

(d)

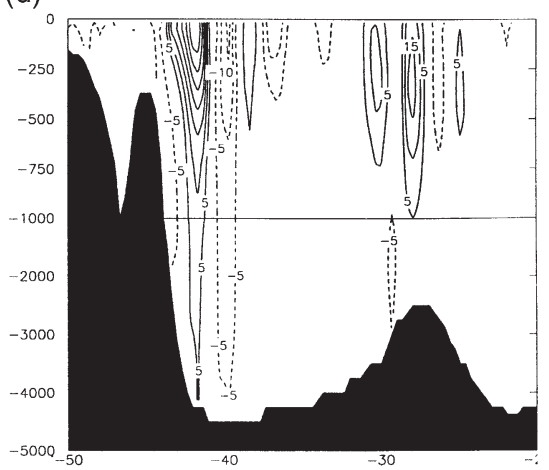

Fig. 4. Annual mean (1993) meridional velocity $(\mathrm{cm} / \mathrm{s})$ along $48^{\circ} \mathrm{N}$, ci $5 \mathrm{~cm} / \mathrm{s}$, dashed lines negative. (a) control experiment, (b) isopycnal model, (c) isopycnal twin experiment, (d) mean SSH assimilation experiment. In (d), assimilation only occurs west of $30^{\circ} \mathrm{W}$.

We conclude from the fraternal twin experiment that the assimilation of SSH is successful in the upper ocean and leads to a distribution of the physical fields which closely resemble that of the twin experiment. However, below about $1000 \mathrm{~m}$ the method is not effective, and in particular cannot be used here to compensate for systematic errors in a model.

\section{Assimilation of observed mean SSH}

We now investigate to what degree assimilation improves the mean circulation estimate, by comparisons with data, first (showing success for the assimilation) with mean data and then (with less success) with synoptic data.

\subsection{Comparison with mean data}

The temperature section at $48^{\circ} \mathrm{N}$ of the mean SSH assimilation (Fig. 3e) shows a pronounced front at $42^{\circ} \mathrm{W}$. It also shows a systematic shallowing of the isotherms from $40^{\circ} \mathrm{W}$ to $33^{\circ} \mathrm{W}$ which is not seen in the other model runs but is visible in the Boyer and Levitus (1997) climatology 
(though much weaker) and is associated with an expression of a weak southeastward branch of the NAC (cf. Rossby, 1996). Further east over the MAR, the isotherms deepen sharply, an aspect of the simulation which is not supported by observations and the assimilation, which ends at $30^{\circ} \mathrm{W}$, has failed to improve.

A comparison of the velocity fields in the mean SSH assimilation with direct observations is more difficult as ocean currents are highly variable. Direct current measurements at $48^{\circ} \mathrm{N}$ were taken by Arhan, Colin de Verdière and Mercier (1989) who reported on data from 4 moorings at $20,25,30$ and $35^{\circ} \mathrm{W}$, each series covering several years. Generally, the observed flow was more strongly oriented east-west than north-south. The meridional flow was rather weak, of order $1-2 \mathrm{~cm} \mathrm{~s}^{-1}$ at the four locations, with northward flow near-surface at $35^{\circ} \mathrm{W}$ and at depth, and mostly southward flow at the other moorings. Mid-depth $(2500 \mathrm{~m})$ northward velocities were also very weak. There is little agreement with the annual mean meridional velocity from the mean SSH assimilation (Fig. 4d), which either has different sign or is much stronger with currents up to $5 \mathrm{~cm} \mathrm{~s}^{-1}$. Note, however, that the assimilated surface height distribution ends at $30^{\circ} \mathrm{W}$ and so barely extends to the locations of Arhan's observations.

With respect to zonal flows, the situation is greatly improved. Fig. 5 shows the annual (1993) mean eastward velocity from control (Fig. 5a) and mean SSH assimilations (Fig. 5b) at $55^{\circ} \mathrm{W}$. This permits direct comparison with Richardson's (1985) data and those of Bower and Hogg (1996). Richardson (1985) showed a maximum eastward surface flow of $28 \mathrm{~cm} \mathrm{~s}^{-1}$ at $40^{\circ} \mathrm{N}$. The region of eastward surface flow was wide, extending at least between 36 and $43^{\circ} \mathrm{N}$; the westward surface countercurrent was almost absent. The stream width decreased monotonically with depth and tilted southwards, so that the maximum eastward flow at $4000 \mathrm{~m}$ was $6.8 \mathrm{~cm} \mathrm{~s}{ }^{-1}$ at $37.5^{\circ} \mathrm{N}$ (thus at $40^{\circ} \mathrm{N}$, the deepest recorded current was westward). The countercurrent was centred around $36^{\circ} \mathrm{N}$ and was approximately equivalent-barotropic. Bower and Hogg (1996) noted that Richardson's data were drawn from a variety of sources, whereas their later data were entirely from moored current meters. Their 1987 SYNOP data showed a zonal jet which was more concentrated than Richardson's picture, being narrower $(400 \mathrm{~km})$, stronger (surface flow of 35-40 cm/s), and more vertically aligned than his estimates (the horizontal velocity maximum always lay between 39 and $\left.40^{\circ} \mathrm{N}\right)$. They found eastward flow south of the main jet to the limit of their section $\left(37^{\circ} \mathrm{N}\right)$, and a deeper penetration of the jet $(10 \mathrm{~cm} / \mathrm{s}$ at $1000 \mathrm{~m}$ depth). Bower and Hogg also showed a countercurrent below $500 \mathrm{~m}$ north of $40^{\circ} \mathrm{N}$.

The control run shows a northward shift of the Gulf Stream at about $55^{\circ} \mathrm{W}$, so that the maximum eastward surface velocities occur at about $42^{\circ} \mathrm{N}$, rather than at $40^{\circ} \mathrm{N}$ as found by both Richardson and Bower and Hogg. The area of maximum current is approximately equivalent-barotropic, with weak areas of countercurrents to north and south (the southern countercurrent having only a weak surface expression). Further south, between 35 and $40^{\circ} \mathrm{N}$, there is a wide area of surface eastward flow with a westward countercurrent beneath, which reaches $2.5 \mathrm{~cm} \mathrm{~s}^{-1}$. Thus the control run in no way reproduces the observational findings.

In contrast, the mean SSH zonal velocity is considerably closer to reality. Its maximum surface flow occurs at $40^{\circ} \mathrm{N}$ and, at $40 \mathrm{~cm} \mathrm{~s}^{-1}$, is similar in strength and location as the observations. The latitudinal extent of the assimilated Gulf Stream width is almost exactly matches that observed at the surface, extending $2^{\circ} \mathrm{N}$ and $\mathrm{S}$ of $40^{\circ} \mathrm{N}$. As in the observations, there is little surface signature of the countercurrent, which is only poorly reproduced and partitioned too far north. The assimilation does produce an equivalent-barotropic structure in the vertical, with the $10 \mathrm{~cm} / \mathrm{s}$ contour 

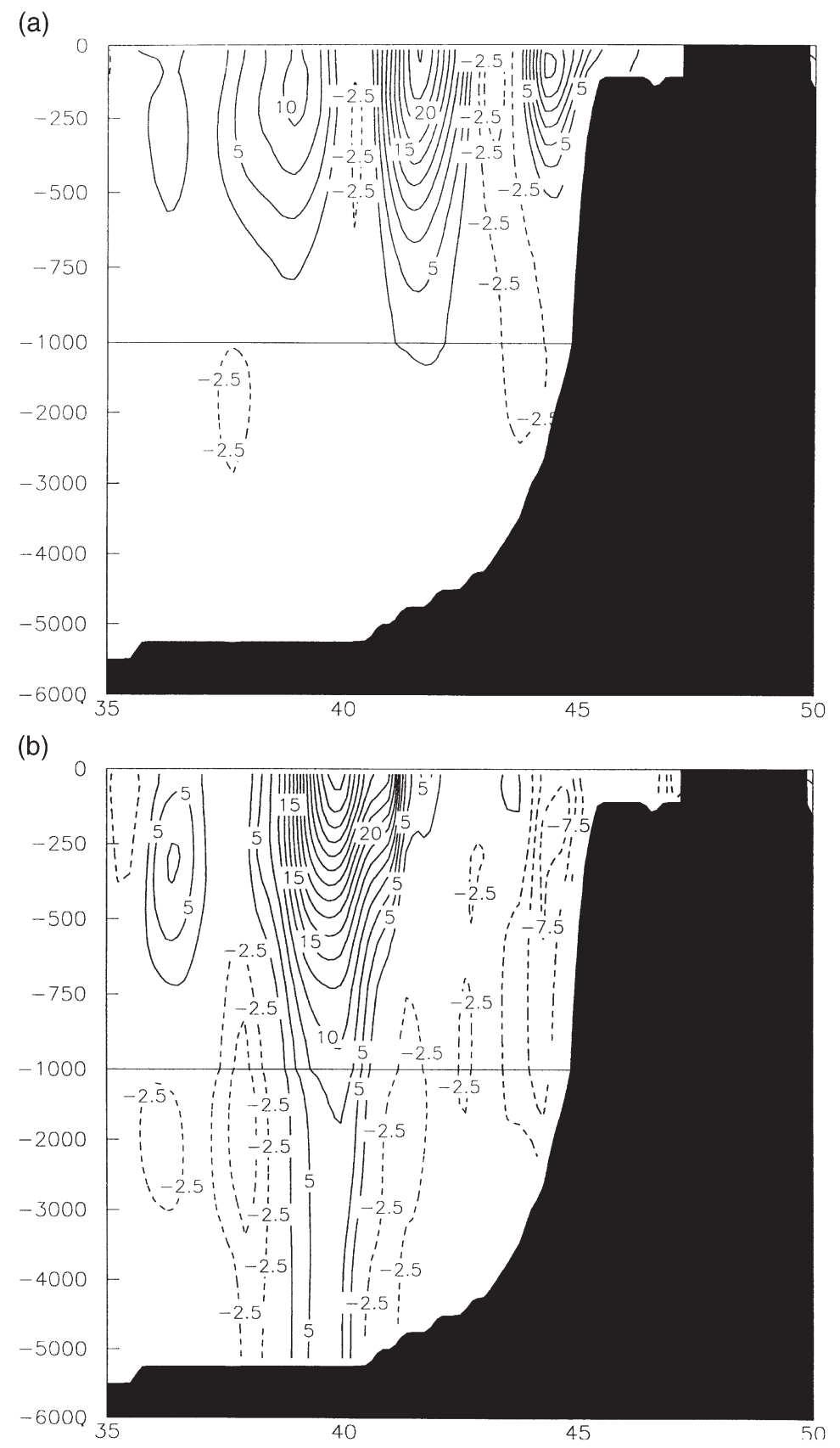

Fig. 5. Annual mean (1993) zonal velocity (cm/s) along $55^{\circ} \mathrm{W}$, ci $2.5 \mathrm{~cm} / \mathrm{s}$, dashed lines negative. (a) control, (b) mean SSH assimilation experiment. 
at the same depth as in the observations, and also shows no reversal of current south of the main jet, once again in agreement with observations. The $5 \mathrm{~cm} / \mathrm{s}$ contour extends only slightly deeper in the model than in the observations.

This degree of agreement is rather impressive. Certainly the Singh and Kelly (1997) SSH would provide a surface geostrophic flow in reasonable accord with Richardson's (1985) and Bower and Hogg's (1996) data since many of the data sources would be common. Thus this degree of agreement for the surface flow may not be surprising. But the observed good agreement at depth requires thermal wind to hold accurately with depth, which in turn requires good performance of the assimilation scheme.

In confirmation, Fig. 6 shows the temperature structure at the same location, and may be compared with Hall and Fofonoff's (1993) data taken at the same time as the SYNOP velocity data. The control run shows the thermal front too far north, although in the actual latitude of the main jet $\left(40^{\circ} \mathrm{N}\right)$ the stratification is quite reasonably reproduced, with potential temperatures of $14^{\circ} \mathrm{C}$ at $500 \mathrm{~m}$, and $5.5^{\circ} \mathrm{C}$ at $1000 \mathrm{~m}$. The lack of a front is clearly demonstrated: almost the same values hold for the more southern latitude of $39^{\circ} \mathrm{N}$, whereas the values observed are 16.5 and $6^{\circ} \mathrm{C}$ respectively. In the mean $\mathrm{SSH}$ assimilation, however, (Fig. 6b), while the actual values are somewhat in error $\left(10\right.$ and $4.5^{\circ} \mathrm{C}$ at 500 and $1000 \mathrm{~m}$ at $40^{\circ} \mathrm{N}, 14$ and $5.5^{\circ} \mathrm{C}$ at the same depths at $39^{\circ} \mathrm{N}$ ), the thermal front is reproduced well, centred accurately at $40^{\circ} \mathrm{N}$.

The stream function of the annual average of vertically integrated transport is shown in Fig. 7. The control run (Fig. 7a) is characterised, in addition to the transport associated with the Gulf Stream and its extension, by a number of anticyclonic recirculations on the warm side. It almost completely lacks a cyclonic circulation on the cold side. The mean SSH assimilation (Fig. 7b) is more realistic in several aspects. The Gulf Stream path is moved south, the unrealistic anticyclonic eddy downstream of Cape Hatteras is much reduced, and the well-known anticyclonic circulation near $42^{\circ} \mathrm{W}, 43^{\circ} \mathrm{N}$ is well developed. Also, on the cold side the assimilation has established a cyclonic circulation which reaches more than $20 \mathrm{~Sv}$ between $63^{\circ} \mathrm{W}$ and $53^{\circ} \mathrm{W}$. On the other hand, two pronounced anticyclonic recirculations on the warm side, at $65^{\circ} \mathrm{W}$ and $58^{\circ} \mathrm{W}$, respectively, which are present though much weaker in the control run, are probably less realistic. The difference map (Fig. 7c) shows that almost no changes to the transport occur outside the region of the Western Boundary Current; thus again we see that the induced changes are local in effect.

\subsection{Comparison with a synoptic hydrographic section}

The choice of 1993 for the assimilation period presents a convenient opportunity to examine the simulation of a synoptic hydrographic section, rather than with time-mean data presented earlier. In July, 1993, the FS Gauss occupied a section between 42 and $49^{\circ} \mathrm{N}, 50$ and $10^{\circ} \mathrm{W}$ between (respectively) July 7 and July 25, 1993. The section was oriented approximately SE between 50 and $45^{\circ} \mathrm{W}$, then $\mathrm{NE}$ east of $45^{\circ} \mathrm{W}$.

During the survey, several surface features crossed the track of the section, as shown in Fig. 8 , which also shows the location of the section. The two most intense features were a negative anomaly of about $20 \mathrm{~cm}$ that remained approximately stationary at $34^{\circ} \mathrm{W}$, and a positive anomaly of about $15-20 \mathrm{~cm}$, that moved northwards across the track at about $39^{\circ} \mathrm{W}$ during the month. The mean SSH assimilation reproduced the features well (Fig. 8a; they were not reproduced by the control run. 

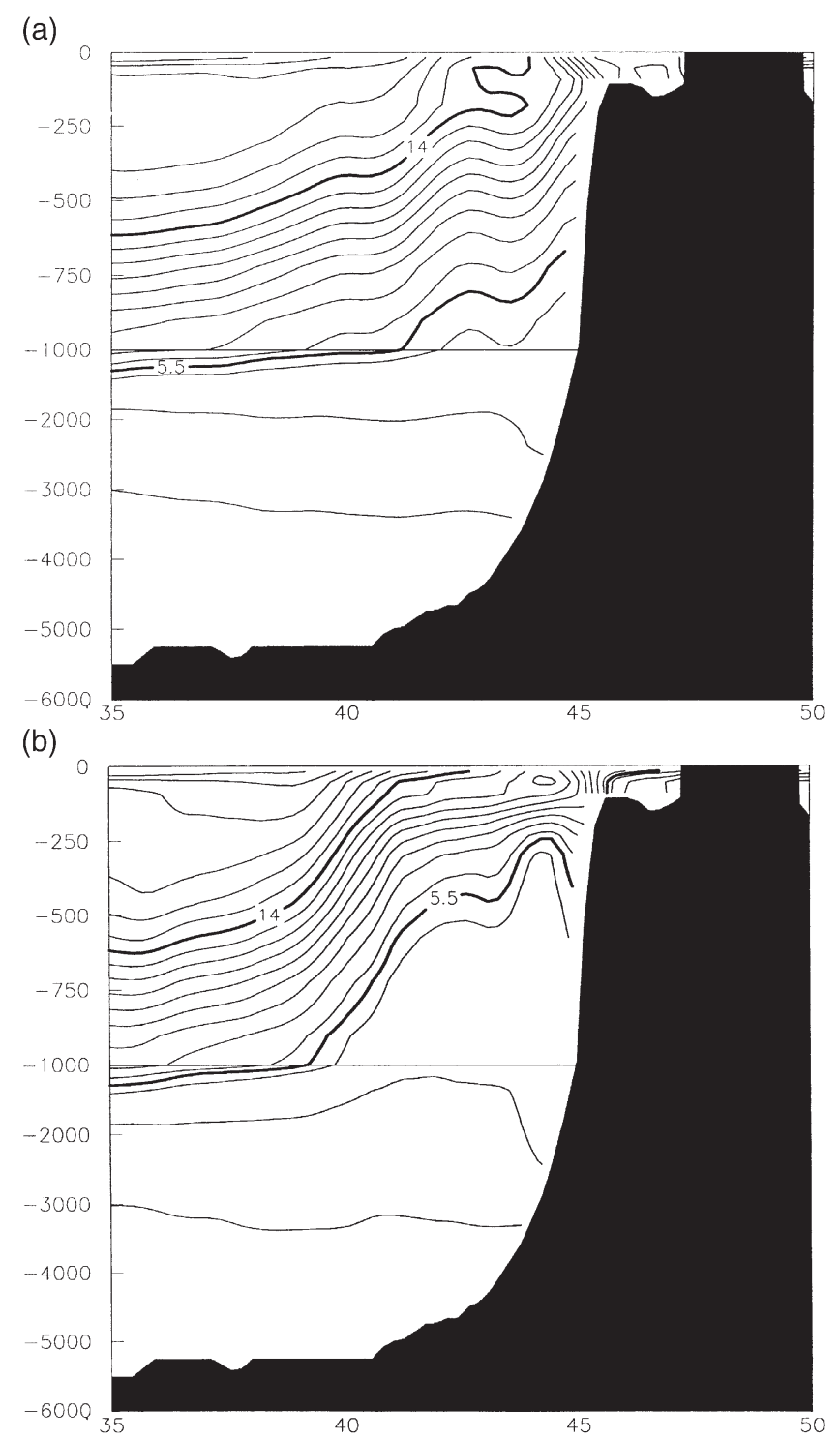

Fig. 6. Annual mean (1993) potential temperature $\left({ }^{\circ} \mathrm{C}\right)$ along $55^{\circ} \mathrm{W}$, ci $1^{\circ} \mathrm{C}$, thick line shows $10^{\circ} \mathrm{C}$. (a) control, (b) mean SSH assimilation experiment. An extra (thick) contour at $5.5^{\circ} \mathrm{C}$ is added.

Observations and all model results, shown in Figs. 9 and 10, possess the same overall $T-S$ structure, with a strong thermocline between 500 and $1000 \mathrm{~m}$, and a lens of warm saline water occupying the top $500 \mathrm{~m}$ between 40 and $48^{\circ} \mathrm{W}$. (Although the lens extended much too far to the east in the simulations.) This is to be expected, since the models are initiated from Levitus data which represents the large-scale water mass structure well. However, no assimilation runs, nor the control run, possess sufficiently sharp thermal and haline vertical gradients, which are very sensitive to details of vertical mixing. Nor do they possess the sharp horizontal gradients 
(a)

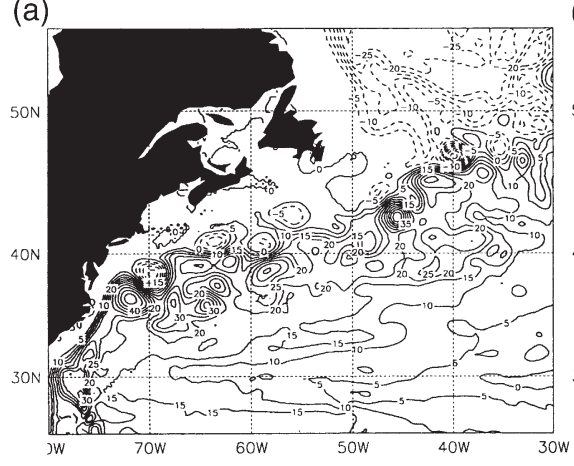

(b)

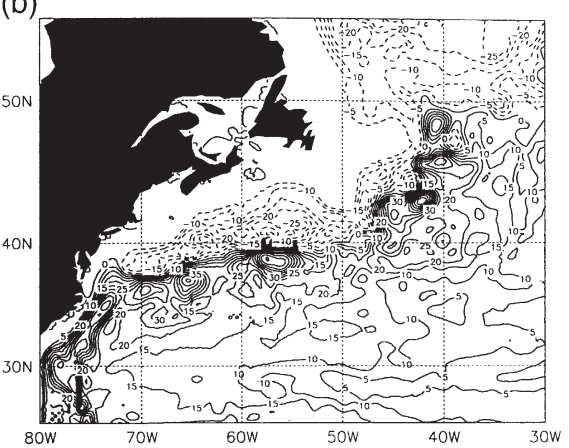

(c)

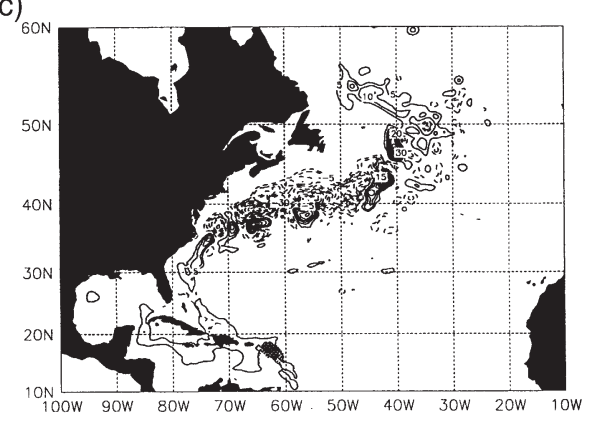

Fig. 7. Annual mean barotropic stream function (Sv), ci 5 Sv. (a) Control run, (b) Mean SSH assimilation, (c) difference mean SSH assimilation - control run. No zero line is shown in (c) for clarity.

associated with frontal features. Salinity and temperature anomalies are approximately densitycompensated.

In the western part of the section, there is little evidence that assimilation has modified subsurface structure at all. Subsurface temperature errors are several degrees too warm, associated with the large-scale misplacement of the Gulf Stream extension. At $45^{\circ} \mathrm{W}$ (eastern end of the western part) temperatures at 500-750 m are over $2^{\circ}$ too cold in all assimilation runs, compared with $2^{\circ}$ too warm in the control run. Similarly, the salinities are up to $0.4 \mathrm{psu}$ too saline (western side) or too fresh (eastern side). The general upward shift of the thermocline at the eastern side in the assimilation runs appears to be associated with a negative altimetric SSH anomaly of about 20 $\mathrm{cm}$, approximately stationary at $34^{\circ} \mathrm{W}$, and the disappearance of the strong cyclonic feature at $42^{\circ} \mathrm{N}, 45^{\circ} \mathrm{W}$ in the control experiment.

In the eastern part of the section, the observations show evidence of a multiple eddy structure, with a cold eddy at $35^{\circ} \mathrm{W}$, a warm eddy at about $32^{\circ} \mathrm{W}$, and further cold features at $30^{\circ}, 27^{\circ}$ and $23^{\circ} \mathrm{W}$. None of these are well aligned with the observed SSH features. The control run possesses similar features, which are much weaker and in different locations. The effects of assimilation are quite strong in this region. The water mass structure in the standard assimilation run has a strong cold feature at $42^{\circ} \mathrm{W}$ which is not evident in the data, a cold feature at $34^{\circ} \mathrm{W}$ which is correctly sited and another, a lens-like feature centred at $800 \mathrm{~m}$, correctly sited at $29^{\circ} \mathrm{W}$, but of the wrong strength. Examination of the temperature and salinity differences between observations and the standard assimilation shows that assimilation has improved the temperature structure 
(a)

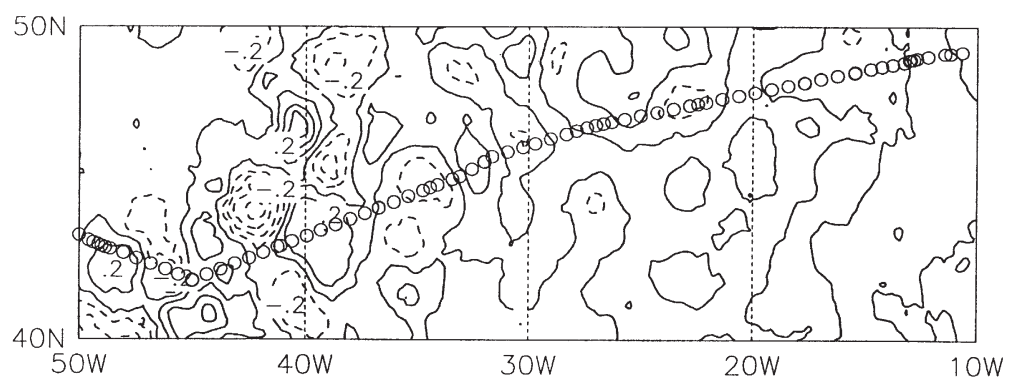

(b)

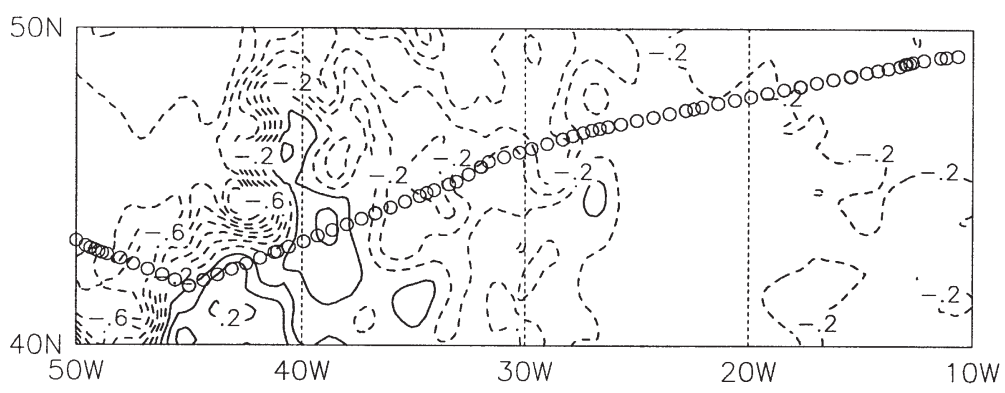

Fig. 8. Sea surface height anomaly (m), ci $0.1 \mathrm{~m}$, on July 27, 1993, over the region of the FS Gauss section, extending from $55^{\circ} \mathrm{W}$ to $10^{\circ} \mathrm{W}$ and $40^{\circ} \mathrm{N}$ to $50^{\circ} \mathrm{N}$. The hydrographic stations occupied by FS Gauss are indicated by circles. (a) The SSH anomaly as observed by ERS-1-TOPEX-POSEIDON. (b) The mean SSH assimilation run.

somewhat, especially in the locations mentioned above, but that severe errors (up to $6^{\circ} \mathrm{C}$ ) remain, with equivalent salinity errors up to $0.5 \mathrm{psu}$. The mean SSH assimilation performs somewhat better at $32^{\circ} \mathrm{W}$, but still fails to place a cold feature at $24^{\circ} \mathrm{W}$.

\section{Conclusion/discussion}

Evaluating the success of an assimilation is difficult, since oceanographers lack sufficient data of either quality or quantity to permit a statistically relevant comparison of prediction and data. Comparison of variability with observations suffers from a double use of the data. We have had to recourse to predominantly non-synoptic data sources here. We have made many comparisons not discussed here. Most single sections and current meter records (not discussed here) are not ideal units for such comparison, in that a small spatial deviation of assimilated solution from data is enough to make results look erroneous.

OW have already shown, and our original experiments confirm, that the representation of ocean variability can be improved by assimilating sea surface height variability. However, such experiments also reveal the undesirable feature that errors in mean model climatology cannot be reduced by using local methods such as OW. Indeed, to stress the point, the improvements generated by assimilation remain local; in the mean $\mathrm{SSH}$ assimilation, there is almost no change in regions 
(a)

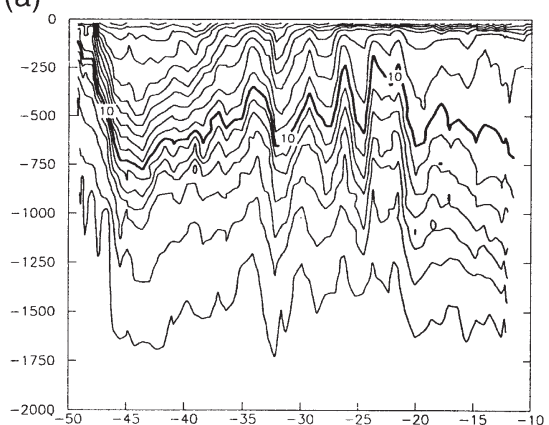

(c)

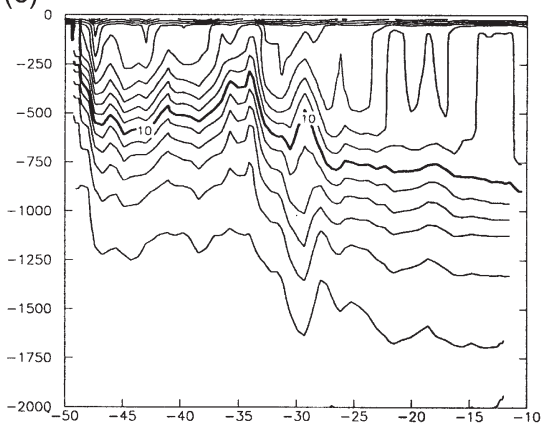

(e)

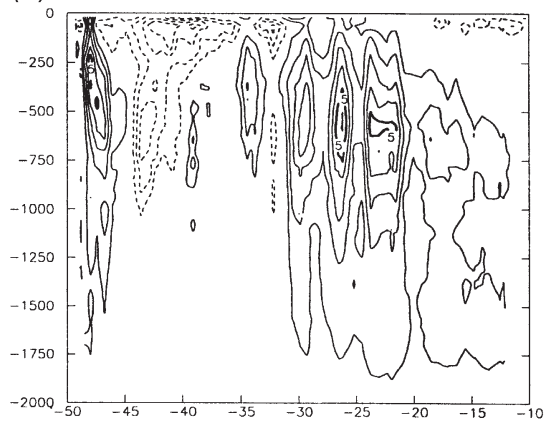

(b)

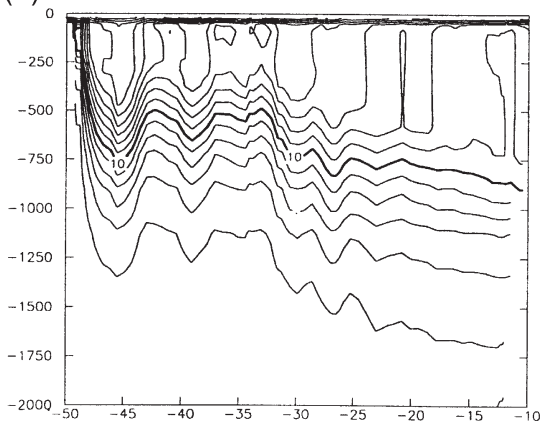

(d)

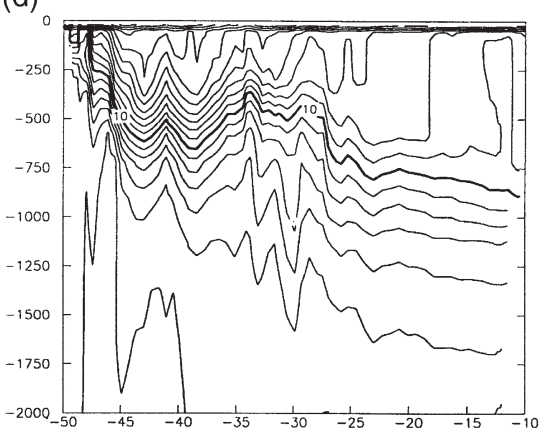

(f)

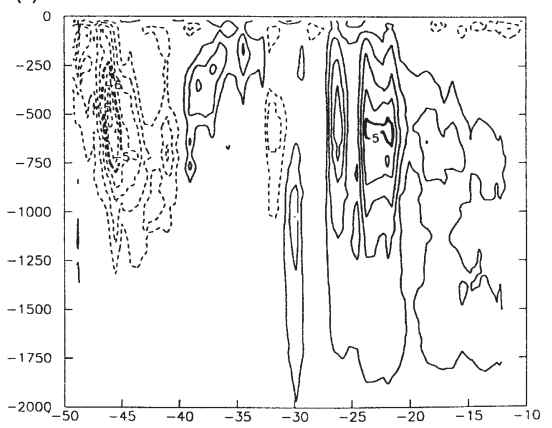

Fig. 9. Potential temperature along the WOCE A 48 section at about $48^{\circ} \mathrm{N}$, ci $1^{\circ} \mathrm{C}$, thick line $10^{\circ} \mathrm{C}$. (a) Observations taken by FS Gauss between July 7 and July 25, 1993. Computed results are for July 27, 1993, and are: (b) simulated potential temperature field of the control experiment, (c) the standard assimilation, (d) the mean SSH assimilation experiment, (e) temperature anomaly for the control run (control - observation), thick lines at $\pm 5^{\circ} \mathrm{C}$, and (f) temperature anomaly for mean SSH.

which are not being assimilated. Such a result is likely to hold for most nonoptimal methods for similar reasons, and it is not clear that even a statistically optimal method would show much impact on the mean fields beyond the region where the data are assimilated, even after a sufficiently long period to differentiate the vertical modal responses.

This implies that some aspect of the ocean mean state needs assimilation in addition to sea surface variability, if errors in that mean state are to be reduced. We can imagine assimilation of in situ temperature and salinity, for example. This could cause difficulties if the model climatology differs from that being inserted, e.g. if boundary current separation is incorrect. 
(a)

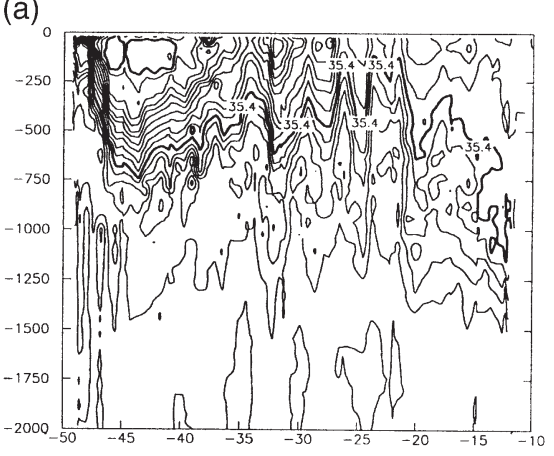

(c)

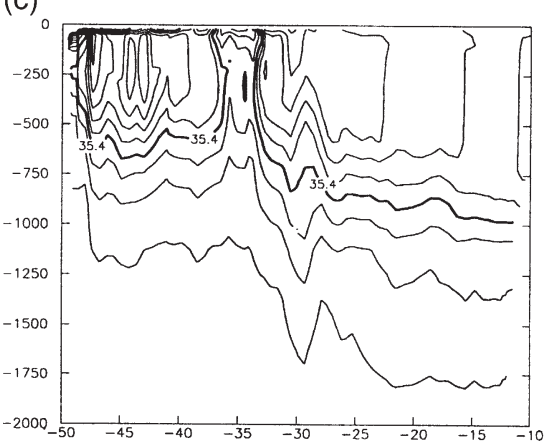

(e)

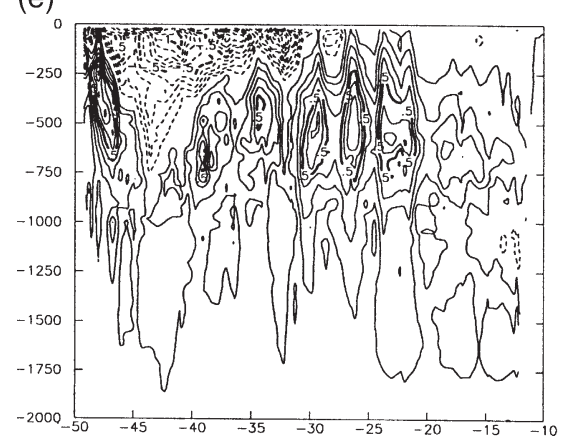

(b)

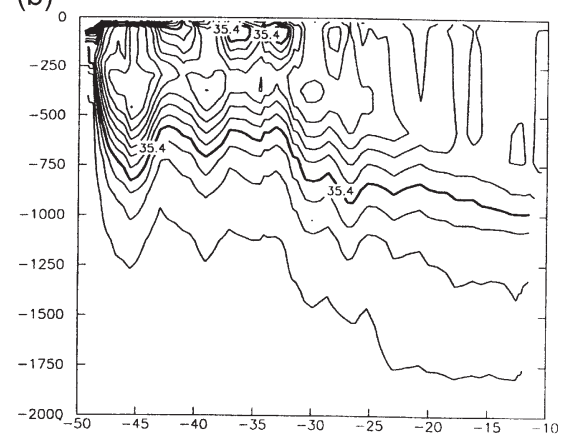

(d)

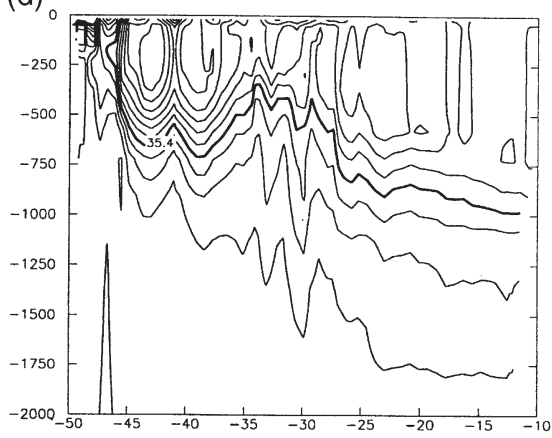

(f)

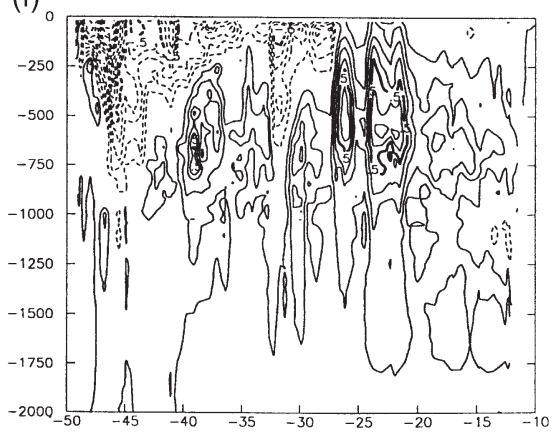

Fig. 10. As for Fig. 9, but for salinity, ci 0.1 psu, thick line 35.4 psu in (a) to (d), \pm 0.5 psu for the anomalies (e) and (f).

Instead, we chose here to define a mean sea surface in various ways, and use this, combined with the observed variability, for assimilation. Selection of a mean surface height has strong implications for the water mass structure of the model, but only in a (vertical) integral sense. One might expect, say, the representation of the first vertical mode to be improved.

In fact, as we have seen, changes to the mean SSH have a strong effect on the entire ocean column. Selection of a mean SSH from another ocean model produces, in some sense, a tendency towards that other model (which will usually be neither more nor less accurate than the original model). We have shown that, conversely, choosing a reasonable representation of the mean SSH invokes strong changes in the model climatology in the direction of reality, including re-alignment 
of the model Gulf Stream, and a more accurate representation down to at least $1000 \mathrm{~m}$. However, water mass structures remain poorly represented when compared against synoptic data in midocean.

We have not yet explained the dynamics of these changes; this topic will be discussed in a later paper. We do not yet know, therefore, the extent to which assimilation of the mean SSH can modify the water mass structure of the assimilated ocean. Climate modellers, and even eddyresolving modellers, are aware of erroneous water masses in their ocean model induced by poor representation of model processes (flows through sills, for example; W01). Would a long-term assimilation of SSH be enough to counter, say, the excessive mixing downstream of the sills in most models? If this turns out to be the case, this would lend extra weight to calls for accurate geoid estimation.

\section{Acknowledgements}

The work reported in this paper is part of the project 'DYNAMO' which has been supported by the European Union Marine Science and Technology programme under contract no. MAS2CT93-0060. This support is gratefully acknowledged. The SLA products are supplied by the CLS Space Oceanography Division, Toulouse, France (AVISO/Altimetry, 1996; Le Traon et al., 1985; Le Traon \& Ogor, 1998) with financial support from the CEO programme (Center for Earth Observation) and Midi-Pyrénées regional council. CD ROMs are produced by the AVISO/Altimetry operations center. The ERS products were generated as part of the proposal 'Joint analysis of ERS-1, ERS-2 and TOPEX/POSEIDON altimeter data for oceanic circulation studies' selected in response to the Announcement of Opportunity for ERS-1/2 by the European Space Agency (Proposal code: A02.F105). We would like to thank our colleagues S. Barnard, A. Beckmann, M. Coulibaly, D. de Cuevas, J. Dengg, Y. Jia, M.-M. Lee, J.-M. Molines, R. Redler, T. Reynaud, and A. Schiller, who contributed to various stages of the project. We also acknowledge the provision of supercomputing facilities by the Rechenzentrum der Universität Kiel, Deutsches Klimarechenzentrum Hamburg, the Atlas Centre at the Rutherford Appleton Laboratory, and the Institut pour le Développement des Ressources en Informatique Scientifique, Centre National de la Recherche Scientifique.

\section{Appendix A. Details of assimilation experiments}

The assimilation experiments were forced with daily ECMWF wind stresses for the October 1992 to October 1993 period of the altimetric data set. This was preceded by a six-year 'spinup' run forced with daily ECMWF wind stresses beginning in autumn 1986. Heat flux terms and the surface restoring for salinity were not changed.

The re-initialisation method here is built around the concept of introducing geostrophically balanced corrections, and therefore it cannot function near the equator. Therefore, the assimilation was switched off between $8^{\circ} \mathrm{N}$ and $8^{\circ} \mathrm{S}$ with a one-degree transition zone. Similarly, no data were assimilated in regions with poor tidal corrections, chosen on visual inspection of the mapped data (the European shelf, the Faeroes and Iceland shelves, and the Abrolhos Bank). 
The geostrophic velocity corrections are horizontally divergent. The next barotropic timestep removes this divergence, but before this occurs there is a divergent 3-d flow which, for numerical reasons, occurs in the lowest grid cell in each column. The errors in the temperature thus produced can be shown to be negligible.

In the 'mean SSH assimilation' experiment, the assimilation is restricted to the region where these data are available, so not perturbing the integration outside the region covered by reliable mean SSH data. A one-degree wide transition zone is included to avoid sudden changes. Within the data region, the uncertainty in the mean SSH field has to be considered in the weighting coefficients. This was done in a rather pragmatic way by adding 0.1 to the relative error variances computed for the mapped residuals, up to the maximum value of 1, effectively a similar but slightly larger error distribution to the standard assimilation experiment.

After most computations were completed, it was discovered that the barotropic component of the meridional flow through the open southern boundary condition had the incorrect sign in all experiments using daily wind forcing. The error was discovered too late to be modified, so we chose for consistency to maintain it in all the calculations presented here. Clearly this error modifies northward heat transport and meridional overturning values. However, we do not believe that this error plays any role in either the more local features or the aspects of surface circulation to be discussed below.

\section{References}

Arhan, M., Colin de Verdière, A., \& Mercier, H. (1989). Direct observations of the mean circulation at $48^{\circ}$ N. Journal of Physical Oceanography, 19, 161-181.

Barnier, B., Siefridt, L., \& Marchesiello, P. (1995). Thermal forcing for a global ocean circulation model using a threeyear climatology of ECMWF analyses. Journal of Marine Systems, 6, 363-380.

Bower, A. S., \& Hogg, N. G. (1996). Structure of the Gulf Stream and its recirculation at $55^{\circ}$ W. Journal of Physical Oceanography, 26, 1002-1022.

Boyer, T. P., \& Levitus, S. (1997). Objective analyses of temperature and salinity for the world ocean on a 1/4 degree grid. NOAA Atlas NESDIS 11. Washington, DC: U.S. Government Printing Office.

Capotondi, A., Holland, W. R., \& Malanotte-Rizzoli, P. (1995a). Assimilation of altimeter data into a quasigeostrophic model of the Gulf Stream system. Part I: dynamical considerations. Journal of Physical Oceanography, 25, $1130-1152$.

Capotondi, A., Holland, W. R., \& Malanotte-Rizzoli, P. (1995b). Assimilation of altimeter data into a quasigeostrophic model of the Gulf Stream system. Part II: assimilation results. Journal of Physical Oceanography, 25, 1153-1173.

Cooper, M., \& Haines, K. (1996). Data assimilation with water property conservation. Journal of Geophysical Research, 101, 1059-1077.

Evensen, G., \& Van Leeuwen, P. J. (1996). Assimilation of Geosat altimeter data for the Agulhas Current using the ensemble Kalman filter with a quasigeostrophic model. Monthly Weather Review, 124, 85-96.

Ezer, T., \& Mellor, G. L. (1994). Continuous assimilation of Geosat altimeter data into a 3-dimensional primitive equation Gulf-Stream model. Journal of Physical Oceanography, 24, 832-847.

Fox, A., \& Haines, K. (1996) Altimeter data assimilation in the OCCAM model. Sigma, No. 21, 3-5 (unpublished ms). 
Fukumori, I. (1995). Assimilation of TOPEX sea level measurements with a reduced-gravity, shallow water model of the tropical Pacific Ocean. Journal of Geophysical Research, 100, 25027-25039.

Ghil, M., Cohn, S., Tavantzis, J., Bube, K., \& Isaacson, E. (1981). Application of estimation theory to numerical weather prediction. In L. Bengtson, M. Ghil, \& E. Kallen, Dynamic meteorology: data assimilation methods (pp. 139-224). Springer-Verlag.

Ghil, M., \& Malanotte-Rizzoli, P. (1991). Data assimilation in meteorology and oceanography. Advances in Geophysics, $33,141-265$.

Hall, M. M., \& Fofonoff, N. P. (1993). Downstream development of the Gulf Stream from $68^{\circ} \mathrm{W}$ to $55^{\circ} \mathrm{W}$. Journal of Physical Oceanography, 23, 225-249.

Holland, W. R., \& Malanotte-Rizzoli, P. (1989). Assimilation of altimeter data into an ocean circulation model: space versus time resolution studies. Journal of Physical Oceanography, 19, 1507-1534.

Hurlburt, H. E., Fox, D. N., \& Metzger, E. J. (1990). Statistical inference of weakly correlated subthermocline fields from satellite altimeter data. Journal of Geophysical Research, 95, 11,375-11,409.

Le Dimet, F. X., \& Talagrand, O. (1986). Variational algorithms for analysis and assimilation of meteorological observations: Theoretical aspects. Tellus, 38A, 97-110.

Lemoine, F. G, Smith, R., Smith, D. E., Klosko, S. M., Torrence, M. H., Williamson, R. G., Rapp, R. H., Wang, Y. M., Pavlis, E. C., Nerem, R. S., Chinn, D. S., Pavlis, N. K., Rachlin, K. E., Cox, C. M., Kunz, L., Kenyon, S. C., Salman, R., \& Trimmer, R. (1997). The development of the NASA GSFC and NIMA joint geopotential model. In Gravity, geoid and marine geodesy, International Symposium, Tokyo, Japan, September 30-October 5 1996, pp. 461-469.

Le Traon, P. Y., Gaspar, P., Bouyssel, F., \& Makhmara, H. (1995). Using TOPEX-POSEIDON data to enhance ERS1 orbit. Journal of Atmospheric and Oceanic Technology, 12, 161-170.

Le Traon, P. Y., \& Ogor, F. (1998). ERS-1 orbit improvement using TOPEX/POSEIDON: the $2 \mathrm{~cm}$ challenge. Journal of Geophysical Research, 103, 8045-8057.

Le Traon, P. Y., Rouquet, M. C., \& Boissier, C. (1990). Spatial scales of mesoscale variability in the North Atlantic as deduced from Geostat data. Journal of Geophysical Research, 95, 20267-20285.

Massmann, F. H., Reigber, C., Kning, R., Raimondo, J. C., \& Rajasenan, C. (1993). ERS-1 orbit information provided by D-PAF. In Proceedings of the Second ERS-1 Symposium, ESA, Hamburg, 11-14 October 1993.

Nouel, F., Berthias, J. P., Deleuze, M., Guitart, A., Laudet, P., Piuzzi, A., Pradines, D., Valorge, C., Dejoie, C., Susini, M. F., \& Taburiau, D. (1994). Precise CNES orbits for TOPEX/-POSEIDON: is reaching $2 \mathrm{~cm}$ still a challenge? Journal of Geophysical Research, 99, 24405-24420.

Oschlies, A., \& Willebrand, J. (1996). Assimilation of Geosat altimeter data into an eddy-resolving primitive equation model of the North Atlantic Ocean. Journal of Geophysical Research, 101, 14175-14190.

Richardson, P. L. (1985). Average velocity and transport of the Gulf Stream near 55 W. Journal of Marine Research, 43, 83-111.

Rossby, T. (1996). The North Atlantic Current and surrounding waters: at the crossroads. Reviews of Geophysics, 34, 463-481.

Scharroo, R., Wakker, K. F., \& Mets, G. J. (1993). The orbit determination accuracy of the ERS-1 mission. In Proceedings of the Second ERS-1 Symposium, ESA, Hamburg, 11-14 October 1993.

Singh, S., \& Kelly, K.A. (1997). Monthly maps of sea surface height in the North Atlantic and zonal indices for the Gulf Stream using TOPEX/Poseidon altimeter data. Woods Hole Oceanographic Institution Technical Report, WHOI-97$06,50 \mathrm{pp}$.

Stammer, D. (1997). Global characteristics of ocean variability estimated from regional TOPEX/POSEIDON altimeter measurements. Journal of Physical Oceanography, 27, 1743-1769.

Thacker, W. C. (1986). Relationships between statistical and deterministic methods of data assimilation. In Y. K. Sasaki, Variational methods in geosciences (pp. 173-179). Amsterdam: Elsevier Scientific Publishing Co.

Tokmakian, R. T. (1997) The assimilation of satellite altimeter data into a global eddy resolving ocean model. $\mathrm{PhD}$ dissertation, Naval Postgraduate School, Monterey, USA. 174 pp.

Weaver, A. T., \& Anderson, D. L. T. (1997). Variational assimilation of altimeter data in a multilayer model of the tropical Pacific Ocean. Journal of Physical Oceanography, 27, 664-682. 
Willebrand, J., Barnier, B., Böning, C., Dieterich, C., Killworth, P. D., Le Provost, C., Jia, Y., Molines, J.-M., \& New, A. L. (2001). Circulation characteristics in three eddy-permitting models of the North Atlantic. Progress in Oceanography, 48, 123-161.

Wunsch, C., \& Stammer, D. (1995). The global frequency-wavenumber spectrum of oceanic variability estimated from TOPEX/POSEIDON altimetric measurements. Journal of Geophysical Research, 100, 24895-24910. 